\title{
Grandes intervenções urbanas: acupuntura urbana ou gentrificação?
}

Great urban interventions: urban acupuncture or gentrification?

Las grandes intervenciones urbanas: ¿la acupuntura urbana o la gentrificación?

\author{
Douglas Gallo
}

Professor Mestre - IFSP, Doutorando em urbanismo, PROURB/FAU/UFRJ, Brasil. douglas.luciano@yahoo.com.br

Fábio Silva Santos

Historiador, Mestre em Relações Internacionais, Universite D'Aux-Marseille-I, Brasil. fabiofrancesilva@yahoo.com.br 


\section{Introdução}

Após anos de abandono e de projetos não executados a área portuária do Rio de Janeiro veio ganhando destaque no cenário de preparação para os grandes eventos (Copa do Mundo de Futebol e especialmente os Jogos Olímpicos e Paralímpicos). A área em questão sempre foi um espaço potencial para investimentos, devido seu grande estoque imobiliária, acessibilididade e proximidade à região central da cidade. Em 2009 a prefeitura da cidade lançou o projeto de revitalização Porto Maravilha, fundamentado na preparação dos megaeventos que a cidade realizaria.

Este projeto foi legalmente constituído como uma Operação Urbana Consorciada, englobando principalmente os bairros da Saúde, Gamboa e Santo Cristo, além de partes do Centro e Caju, promovendo a reestruturação urbana local.

O tema da conservação urbana tem ganhado espaço, juntamente com novos parâmetros voltados à gestão urbana nas últimas décadas, crescendo as recomendações internacionais e nacionais. As modificações ocorridas na morfologia de várias cidades do mundo, nas últimas décadas, bem como o entendimento da dificuldade de investimento e planejamento a longo prazo, traz o interesse em discutir as intervenções pontuais, como na acupuntura urbana, com os grandes projetos, muitas vezes relacionados ao city marketing. A diferenciação cultural que o projeto de revitalização do Porto Maravilha procura produzir, ou seja, uma imagem emblemática, uma espécie de marca da cidade, justifica a discussão pretendida.

As políticas e projeto urbanos atuais tem grande preocupação na produção da imagem da cidade como identidade própria, onde, por um lado, a imagem que se vende tem uma distinção e, por outro, a busca pela atração e/ou atenção internacional, levando as cidades a ficarem ainda mais parecidas. Grandes projetos de grandes nomes da arquitetura mundial se multiplicam e podem ser encontrados em várias partes do mundo, produzindo uma homogeneização da imagem das cidades contemporâneas.

\section{Objetivo}

O objetivo do artigo foi discutir o processo de revitalização da região portuária do Rio de Janeiro, baseado em grandes intervenções urbanas, confrontando-o com os conceitos da acupuntura urbana, à luz dos processos de gentrificação e apropriação dos espaços.

\section{Método de análise}

A ideia de confrontar essas grandes intervenções no espaço urbano com o conceito de acupuntura urbana surgir de inquietações e questionamentos em relação à paisagem cultural que tem resultado das intervenções em questão no espaço público. 
É impossível não questionar-se também sobre processos de gentrificação desses espaços. Se a cidade é produzida pelo capital e pela mais valia urbana, e estes espaços ociosos, como no caso da área portuária, representam grande reserva de mercado, é ingenuidade imaginar que a especulação imobiliária não vá se apropriar do espaço e trazer consigo uma gentrificação, ainda mais numa área com forte apelo paisagístico e turístico.

\section{Acupuntura Urbana}

Na medicina tradicional chinesa acupuntura é o conhecimento teórico-empírico que visa à terapia e à cura das doenças através da aplicação de agulhas e de moxas em pontos determinados do corpo. A técnica visa à normalização dos órgãos doentes por meio de um suporte funcional que exerve efeito terapêutico, levando ao equilíbrio das energias (When, 1985).

Embora não concordemos totalmente com a analogia do corpo humano com a cidade, façamos uma análise para entender como o conceito de Acupuntura Urbana expresso por Jaime Lerner (2015) pode ser entendido. O corpo é formado da união de células que dão origem aos tecidos e órgãos, estes por sua vez se associam entre si e coloboram para preservar as funções de locomoção, digestão, defesa, respiração etc. As conexões entre os diversos sistemas é feita pelo sistema nervoso, responsável por coordenar e regular todas as funções e respostas do organismo aos estímulos do meio.

Se a função do sistema nervoso é adequada, ela preserva a adaptação e a saúde do organismo. Sob sua direção o organismo é capaz de prover vários mecanismos de compensação, por isso um sistema nervoso em boas condições é capaz de reagir a lesões com reações compensatórias.

A metáfora da cidade como um organismo vivo foi muito utilizada pelos sanitaristas e higienistas do espaço urbano no século XIX. Amparados pelo pensamento médico, acreditavam que os danos dos ares viciados pelas grandes densidades populacionais contribuiriam para a propagação de doenças contagiosas (Possamai, 2007).

Um dos primeiros pensadores a vincular a cidade à metáfora do organismo foi Claude de Saint Simon (século XIX), para ele a cidade é um organismo vivo permeado por redes que o alimentam e o mantêm em funcionamento. Esta construção teórica entende que existem uma rede material composta pelas trocas de energia e materia prima e uma rede espiritual formada pelo fluxo financeiro (Lemos, 2016).

Se considerarmos a cidade como um organismo vivo, dotada assim de uma energia vital, a analogia de Lerner pode ter um sentido. Para o autor, o princípo de recuperar a energia de um ponto doente ou cansado por meio de um simples toque tem a ver com a revitalização deste ponto e da área ao seu redor. Cutucar uma área de tal maneira que ela possa ajudar a curar, melhorar, criar reações positivas e em cadeia. São vários os exemplos de cidades inovadoras que passaram por tal processo, o qual foi um começo, um despertar, fazendo a cidade reagir 


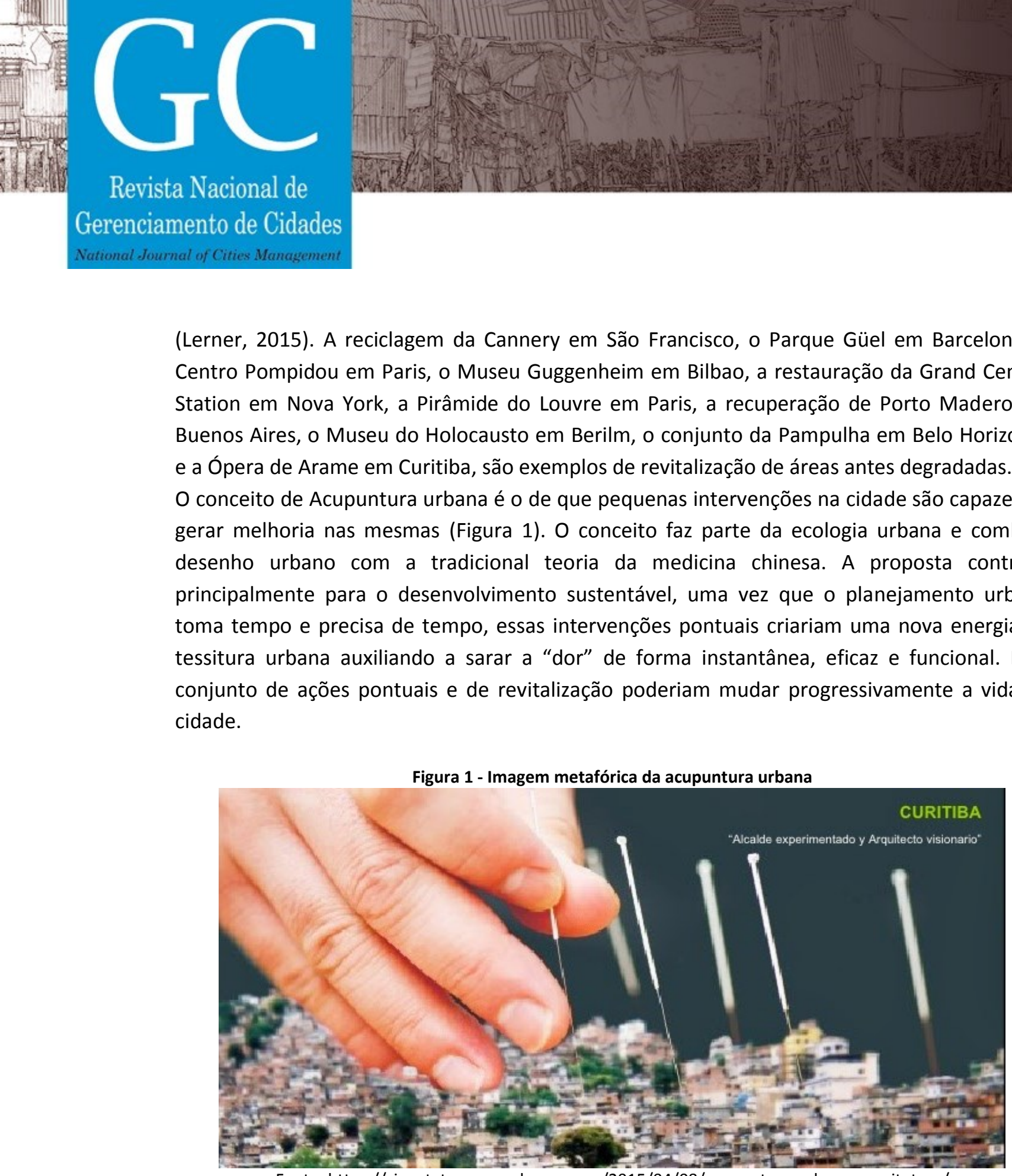
Station em Nova York, a Pirâmide do Louvre em Paris, a recuperação de Porto Madero em Buenos Aires, o Museu do Holocausto em Berilm, o conjunto da Pampulha em Belo Horizonte e a Opera de Arame em Curitiba, são exemplos de revitalização de áreas antes degradadas.

O conceito de Acupuntura urbana é o de que pequenas intervenções na cidade são capazes de gerar melhoria nas mesmas (Figura 1). O conceito faz parte da ecologia urbana e combina desenho urbano com a tradicional teoria da medicina chinesa. A proposta contribui principalmente para o desenvolvimento sustentável, uma vez que o planejamento urbano toma tempo e precisa de tempo, essas intervenções pontuais criariam uma nova energia na tessitura urbana auxiliando a sarar a "dor" de forma instantânea, eficaz e funcional. Esse conjunto de ações pontuais e de revitalização poderiam mudar progressivamente a vida na cidade.

Fonte: https://siagutatemp.wordpress.com/2015/04/08/acupuntura-urbana-arquitetura/

Segundo Lerner (2015), atualmente as cidades do mundo apresentam problemas semelhantes, e os três principais desafios são a mobilidade, a sustentabilidade e a tolerância à sociodiversidade. O planejamento deve ser um ato contínuo na vida das cidades, para que haja equilíbrio entre estes fatores é preciso mesclá-los, uma vez que quanto mais elementos relacionados a essas questões estiverem em jogo, melhor a cidade será. Desta forma aumentará o contato entre as pessoas e a diversidade, contribuindo para que os espaços se tornem mais humanizados.

A cidade como uma relação de funções, de renda, de idade, precisa de diversidade e mistura para ser mais humana e tolerante, evitando os guetos de gente rica ou de gente pobre (Lerner, 2015; Jacobs, 2009). 
Ao olhar para o tecido urbano como um organismo vivo, a acupuntura urbana tem como objetivo principal diminuir o estresse no ambiente urbano por meio de pequenas interações corretivas, é um passo adiante da obra arquitetônica no entendimento coletivo da cidade. A cidade é vista como um núcleo multi-dimensional da energia e do corpo sensorial, e a conexão palpável da natureza humana como porte da natureza. Busca-se alterar assim a "energia" vital da cidade, recolocando-a num bom fluxo energético.

Algumas boas soluções focadas na acupuntura urbana são os espaços verdes, como parques, praças, áreas de lazer, coberturas verdes, jardins verticais e fachada verdes. Deve-se pensar nos fluxos e nas funções dos espaços construídos, procurando gerar e estimular sociabilidades.

\section{Intervenções urbanas e gentrificação}

A reabilitação de áreas centrais transformou-se em uma estratégia de desenvolvimento urbano que conduz ao aprofundamento das desigualdades sociais e espaciais, ao associar políticas públicas e capital imobiliário, utilizando o discurso oficial de agir para o bem de todos, pratica o poder em nome do interesse de classes dominantes em relação às dominadas (Galiza, 2015).

As intervenções urbanas em centros históricos desempenham papel estratégico, tanto no que se refere à melhoria da qualidade de vida urbana de seus moradores e usuários, como em relação à criação de novas condições econômicas capazes de gerar desenvolvimento local, sendo ambas as características importantes para a sustentabilidade da preservação do patrimônio histórico (Bonduki, 2010).

O termo gentrificação é um neologismo anglófilo (gentrification), criado por Ruth Glass para descrever o processo de substituição de moradores de antigos bairros desvalorizados do centro de Londres por famílias de classe média. A gentrificação tornou-se a forma dominante do urbanismo contemporâneo, assim como a política urbana das grandes cidades ocidentais, articulando parcerias financeiras público privadas (Galiza, 2015).

No final do século XX a gentrificação passou a ser uma estratégia urbana global, formando uma aliança concertada e sistemática do urbanismo público e do capital, privado e público. Ao ocupar o vazio deixado pelo retraimento das políticas urbanas progressitas do passado foram sistematicamente afetadas pela crise econômica dos anos setenta e pelos governos conservadores dos anos oitenta (Smith, 2006).

Ao tratar de projetos de reabilitação de áreas centrais, Ermínia Maricato (2002) reconhece que a contenção do processo de valorização que gera a especulação é tarefa difícil e necessária se se deseja agir na direção da justiça social na cidade. A garantia do direto à cidade para os mais pobres é um desafio no Brasil.

Os programas de reabilitação urbana desenvolvidos ao longo da segunda metade do século XX na Europa pretendiam servir de guia para solucionar uma série de problemas das cidades. Desta forma a disciplina urbanística adquire uma vital importância dentro de um problema 


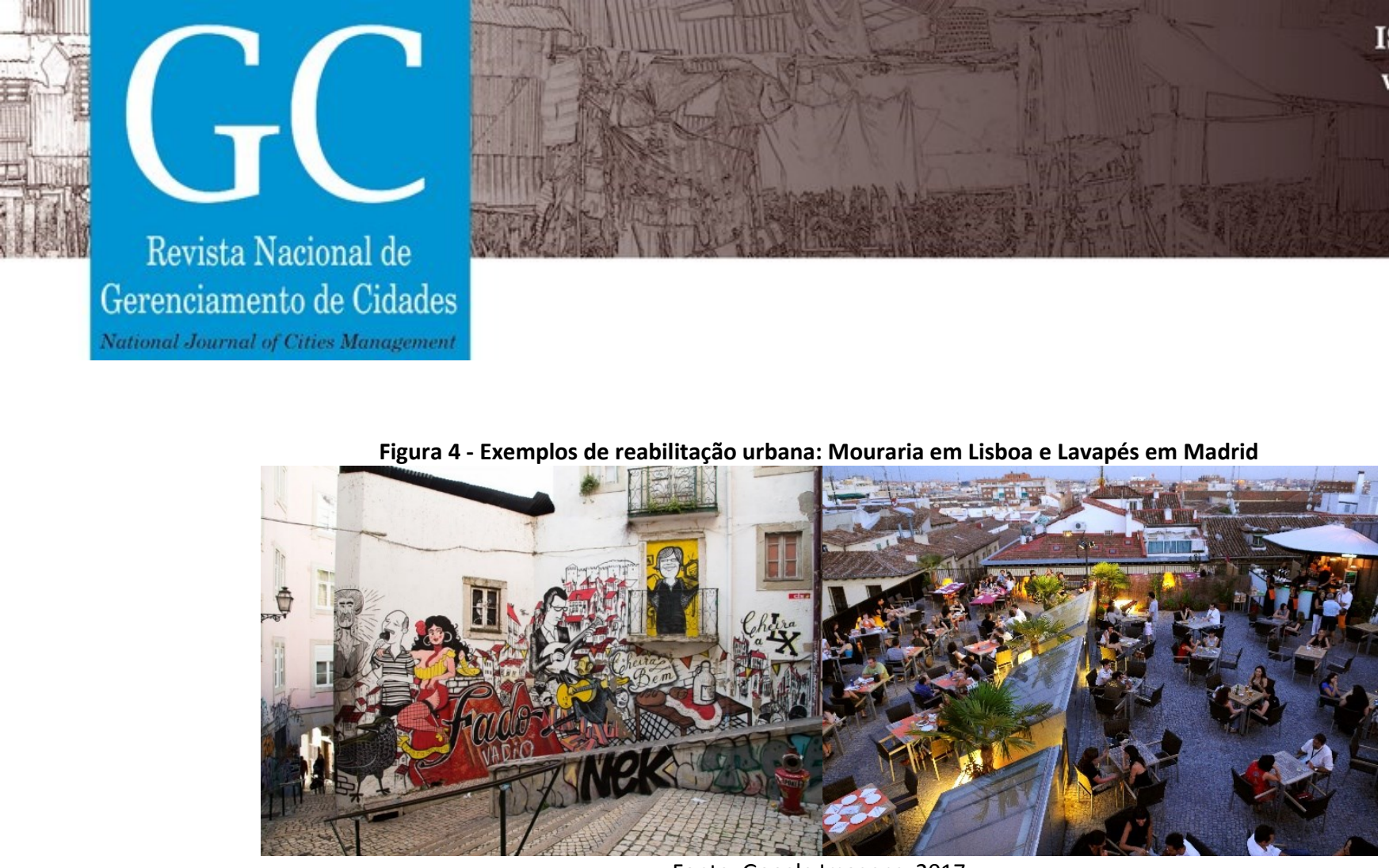

Fonte: Google Imagens, 2017

\section{Rio de Janeiro e o Porto Maravilha}

A zona portuária do Rio de Janeiro abrange os bairros Gamboa, Saúde, Santo Cristo e Caju. 0 seu desenvolvimento ocorreu através de um processo longo e gradativo, caracterizado por desmonte de morros e aterros de áreas alagadas. Até o final do século XVII, a ocupação da cidade estava circunscrita a um quadrilátero formado pelos Morros do Castelo, Santo Antônio, São Bento e Conceição. A zona portuária situava-se fora desse perímetro, tinha uma ligação precária com a malha urbana principal e era considerada periferia da cidade.

Em 1763, o Rio de Janeiro tornou-se a capital do Brasil Colônia, o processo de urbanização acelerou-se enormemente e a cidade expandiu-se para a direção norte. $O$ crescimento da atividade portuária propiciou a ocupação dos morros e planícies de toda a área e a formação dos bairros da Saúde, Gamboa e Santo Cristo. Essa região conhecida como "Pequena África" era considerada a parte mais velha, decadente e pestilenta da cidade. Era o lugar dos escritórios de corretores de escravos, armazéns, depósitos para negros, oficinas e tabernas.

Em 1808 com a vida da família real portuguesa para o Brasil permitiu-se a abertura dos portos para as nações amigas, expandindo as atividades portuárias. 0 processo de urbanização da região se acelerou com a construão de trapiches, manufaturas, casas de fundições etc.

O início do século $X X$, após a abolição da escravidão e a proclamação da República, representou grandes mudanças no país, um crescimento rápido da população urbana e deterioração das condições de moradia. Porém após as grandes transformações do início do século, poucas mudanças ocorreram durante a primeira metade do século XX. Ao longo dos anos, várias propostas de renovação urbana foram apresentadas para a região, mas poucas se concretizaram (Galiza, 2015).

A área portuária também sofreu o esvaziamento populacional que caracterizou a região central da cidade (Figura 5). As causas desse processo abrangem desde a campanha higienista do século XIX até os anos 1970 quando uma lei municipal proibiu novas construções para uso residencial na área central da cidade por um período de quase vinte anos (Galiza, 2015). 
O projeto Porto Maravilha situado na zona portuária do Rio de Janeiro é uma das intervenções urbanas que fazem parte do pacote de grandes obras anunciadas e justificadas pelos governos como exigências para a realização dos megaeventos esportivos da cidade (Copa Mundial de Futebor em 2014 e Jogos Olímpicos e Paralímpicos de 2016). Em decorrência dessas operações urbanas, uma grande quantidade de remoções afetaram famílias pobres que viviam há anos na Zona Oete e na área central da cidade, onde denúncias sobre a violação dos direitos humanos e à moradia poderiam exemplificar o processo de gentrificação dessas áreas da cidade (Galiza, 2015).

No Rio de Janeiro o planejamento urbano de longo prazo tem sido sistematicamente negligenciado. A Operação Urbana Consorciada Porto Maravilha (Figura 6) se configurou como um instrumento para viabilizar ações do "aqui e agora", onde a realização de negócios são mais importantes que o espaço urbano a ser construído. A relação entre a Operação Urbana Consorciada Porto Maravilha e o Plano Diretor do Rio de Janeiro expressa bem esse quadro. 0 grande potecial construtivo e as obras e infraestruturas instaladas na região possuem dois cenários imaginados por Barandier (2015): ou serão subutilizadas e com isso a Caixa Econômica Federal que subsidiou os investimentos não obterá o rendimento esperado ou a operação realmente se viabilizará e o potencial construtivo adicional se realizará plenamente, gerando um outro problema, acarretando um desastre urbanístico enorme, uma vez que a densidade admitida na área é altíssima e baseada em empreendimentos não residenciais. Embora tenham havido grandes transformações, as incertezas quanto ao destino da área portuária ainda são grandes.

Figura 5 - Principais movimentos populacionais provocando esvaziamento da região central e portuária

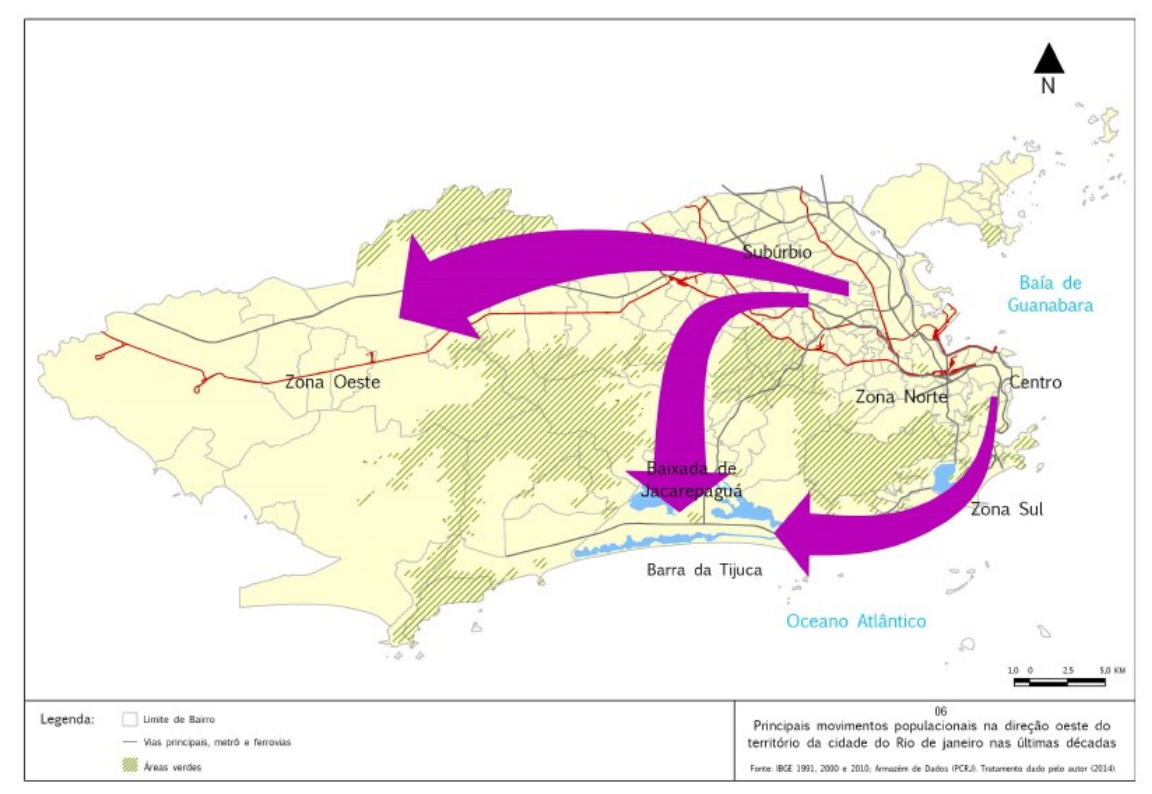

Fonte: Barandier, 2015 


\section{Revista Nacional de}

GALIZA, Helena Rosa dos Santos. Reabilitação de áreas centrais sem gentrificação. Tese (Doutorado em Urbanismo). Rio de Janeiro: FAU/PROUR/UFRJ, 2015.

JACOBS, Jane. Morte e vida de grandes cidades. 2. ed. São Paulo: Martins Fontes, 2009.

LEMOS, André. Cidade-Ciborgue: a cidade na cibercultura. Salvador: FACOM/UFBa, disponível em <http://www.facom.ufba.br/ciberpesquisa/andrelemos/cidadeciborgue.pdf >, acesso em 10 setembro de 2016.

LERNER, Jaime. Acupuntura urbana. Rio de Janeiro: Editora Record, 2015.

MARICATO, Ermínia. Reabilitação de centros urbanos e habitação social. Rio de Janeiro/Petrópolis: Vozes, 125-151, 2002.

POSSAMAI, Zita Rosane. Metáforas visuais da cidade. Urbana, v. 2 (2), 2007.

SEGADO-VÁZQUEZ, Francisco; ESPINOSA-MUÑOZ, Víctor Manuel. La ciudad herida. Siete ejemplos paradigmáticos de rehabilitación urbana en la segunda mitad del siglo XX. Eure, v. 41(123), 103-129, 2015.

SMITH, Neil. A gentrificação generalizada: de uma anomalia local à "regeneração" urbana como estratégia urbana global. São Paulo: Annablume, 59-87, 2006.

WEN, Tom Sintan. Acupuntura Clássica Chinesa. São Paulo: Editora Cultrix, 1985. 